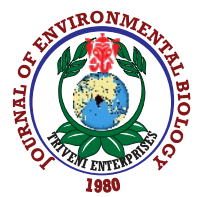

\title{
Toxicity studies of sea anemone (Gyrostoma helianthus) crude extract and fractionated proteins on liver and kidney in rats
}

\author{
Turki M. Al-Shaikh* \\ Department of Biology, College of Science and Arts, University of Jeddah, Khulis, 21959, Saudi Arabia \\ *Corresponding Author Email : tmalshaikh@uj.edu.sa
} \begin{abstract}
parameters in male rats.
Methodology: Live specimens of Gyrostoma helianthus were collected from Jeddah coast, fixed in ethanol, dried and powdered to obtain the crude residue extract. Some of the crude extract were ultra-filtered to produce protein fractions of 1 and $3 K D a$. The $L_{50}$ of crude extract powder was estimated for male rats and momentary repeated subacute dosing $\left(1 / 4 L_{50}\right)$ for 7 days was carried out to obtain toxicity data. Histological examination of liver and kidney sections were carried out. Serum whole protein, total albumin, ALT and LDH were estimated by standard protocol.
\end{abstract}

Abstract

Aim: To study the poisonous effects of crude extract and fractionated protein of sea anemone Gyrostoma helianthus on histological and biochemical

Results: The $\mathrm{LD}_{50}$ of crude extract was $20.32 \mathrm{mg} \mathrm{kg}^{-1}$ for male rats. In acute and subsequent sub-acute toxicity, neurological symptoms such as convulsions, paralysis, tremors, and ataxia were observed overdose exposure. At the end of exposure to subacute dose histopathological changes like hemolyzed blood and atrophy of glomerular tuft in kidney and fatty changes, vacuolation, necrosis, and infiltration in liver was noted. Furthermore, vital significant increase in total protein, ALT and LDH and reduced bilirubin in serum of treated groups was observed as compared to the control.

Interpretation: The present study emphasizes the toxicological, behavioral, biochemical, and histological bioactivity of crude extract and protein fractions of 1 and $3 \mathrm{KDa}$ of Gyrostoma helianthus sea anemone, which is commonly found in the Red Sea. The tested extracts were found

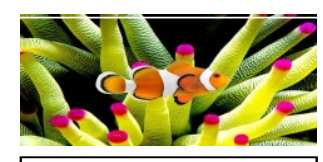
Sea anemone (G. helianthus)

Crude extract Protein fraction $1 \mathrm{KDa}$ Protein fraction $3 \mathrm{KDa}$
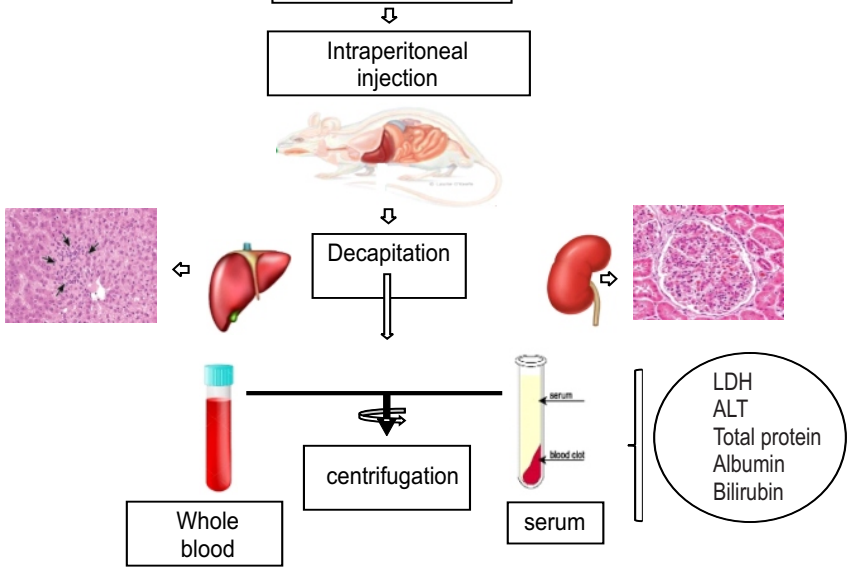

Key words: Biochemistry, Gyrostoma helianthus, Histopathology, Toxicity

How to cite : Al-Shaikh, Turki M.: Toxicity studies of sea anemone (Gyrostoma helianthus) crude extract and fractionated proteins on liver and kidney in rats. J. Environ. Biol., 42, 135-143 (2021). 


\section{Introduction}

Sea anemone, Gyrostoma helianthus is a solitary-living organism from Phylum Cnidaria, Class Anthozoa. They produce distinctive poisonous proteins. According to Frazão et al. (2012) nematocysts of sea anemones possess at least four classes of excessive poisonous supplies whose composition and outcomes have now not been confirmed yet. As reported by Rojko et al. (2016) and Madio et al. (2019) sea anemone venom with more than type of one toxin and most have effective cytolytic effects on invertebrate and vertebrates. In mammals, sea anemone toxins motive distinctive kinds of syndromes, which include hepatic failure (Garcia et al., 1994), nephrotoxicity (Mizuno et al., 2012), cardiotoxicity (Bruhn et al., 2001) and neurotoxicity (Madio et al., 2019). These hazard outcomes vary notably due to difference in susceptibility amongst individuals, toxin awareness and how toxin injures the body. The toxicity of sea anemone toxins has been related with the binding to cell receptor and interrupting cell channel (Suput, 2009), that provoke cell membrane poreformation and cell lysis (Ramírez-Carreto et al., 2019).

Among the exceptional toxicological results of sea anemone venoms, research on the histological effects is still meager mainly on the groundwork of venom protein fractions. Ravindran et al. (2012), reported that the crude extracts and isolated proteins of sea anemone induces sever histopathological changes in heart, kidney, liver and brain tissue of mice. Further, Al-Hazmi et al. (2015) demonstrated that G. helianthus toxins as crude and fractionated protein extracts actively damage neural cells of cerebral cortex. Besides, the histopathological effect, the cytotoxicity and cytolysis impact of exclusive sea anemone toxins attracted tremendous activity (García-Linares et al., 2016; Ramírez-Carreto et al., 2019).

The fundamental characteristic of cell cytolysins via sea anemone toxins in most of the stated information is their capability to shape pores in cell membranes, which lead to cell lysis and death (Anderluh and Macek, 2002; Madio et al., 2019). Frazão et al. (2012), postulated that the destructive cytolytic consequences depending on the toxin type, concentration and molecular characterization. Until recently, the toxicological influence of $G$. helianthus has not been yet fully characterized in liver and kidney, which are important organs of metabolism, detoxification, storage, and excretion of toxic sources and are specifically prone to damage. In view of the above, this study was carried out assess, the histopathological and biochemical effects of crude and two protein fractions from $G$. helianthus amassed from the Red sea coast, Saudi Arabia, Jeddah effects.

\section{Materials and Methods}

Sample collection and preparation of crude extract: Live specimens of sea anemone ( $G$. helianthus) were collected, rapidly washed, and weighed and finely ground for $3 \mathrm{~min}$ in absolute ethanol in a ratio of equal weight per volume. The blended material was once centrifuged at $15,000 \mathrm{rpm}$ for $10 \mathrm{~min}$ at $4^{\circ} \mathrm{C}$, and the first supernatant used to be preserved for following steps. Pellets have been extracted for 2 nd time in an absolute ethanol (2- supernatant) and the third step of extraction was once executed in 50\% aqueous ethanol (3- supernatant). The three supernatants have been delivered to each other and then the supernatants had been evaporated below pressure at $40^{\circ} \mathrm{C}$ in an evaporator. Then the got extracts had been dried in a freezer to get the final crude extract.

Isolation and partial purification of crude extract: Fractionation of ethanolic extract of $G$. helianthus and its purification was carried out by Molecular Weight Exclusion Ultrafiltration: Crude extract was filtered once via membrane filters with cut off $3 \mathrm{kDa}$ and $1 \mathrm{kDa}$ (76 $\mathrm{mm}$ in diameter).

Animal maintenance and treatments: Adult male albino rats (Rattus norvegicus) weighing (150-170 g) had been chosen and housed underneath hygienic conditions and a photoperiod of 12 $\mathrm{hr}$ (day/night). The animals had been divided into 5 groups, the first was used for estimating the lethal dose $\left(L_{50}\right)$ of the crude extract by intraperitoneal injection with successive increasing doses (3-30 mg kg ${ }^{-1}$ ). After administration of the treatment,dead animals were counted $24 \mathrm{hr}$. latter and the $L_{50}$ value was calculated as described by Litchfield and Wilcoxan method(1949). Throughout toxicity test, events statement of neuropathology and motor activity was recorded.

As Jeddah University is a newly established university in Saudi Arabia, animal ethical committee is not fully functional. However, animal remedies and handling during the experiment was carried out following the codal formalities of Jeddah University Ethical Committee.

After estimating $L_{50}, 4$ groups of animals (10 animals each) were divided as follows: Control group was once intraperitoneally injected with $0.5 \mathrm{ml}$ of saline solution for seven days. Group two were intraperitoneally injected with the crude extract $\left(5.08 \mathrm{mg} \mathrm{kg}^{-1}\right)\left(1 / 4 \mathrm{LD}_{50}\right)$ for seven days. The animals of $3^{\text {rd }}$ and $4^{\text {th }}$ groups were intraperitoneally injected with the protein fraction of either $1 \mathrm{KDa}$ or $3 \mathrm{KDa}$ at all identical dose of crude extract and for the same experimental period.

Histopathological examination: As described by Humason (1978) and after completion of treatment, the experimental animals were sacrificed via cervical dislocation. Slices of right liver lobe and right kidney from 7 control and treated groups were dissected cautiously and fixed in $10 \%$ formalin for $24 \mathrm{hr}$. Washing was done with tap water and then serial dilutions of alcohol (methyl, ethyl, and absolute ethyl) were used for dehydration. Specimens were cleared in xylene, embedded in paraffin at $56^{\circ} \mathrm{C}$ in warm air oven for $24 \mathrm{hr}$. Paraffin wax tissue blocks were organized for sectioning at $5 \mu \mathrm{m}$ thickness by way of sliding microtome, routinely stained with hematoxylin and eosin (H\&E) and histological commentary were assayed and photographed under a light microscope (Labomed, CXII). 
Serum biochemical analysis: At the end of the experimental period, blood was collected in tubes, centrifuged at $5000 \mathrm{rpm}$ for $15 \mathrm{~min}$ and stored at $4^{\circ} \mathrm{C}$ for biochemical assay analyses. The serum range of total bilirubin, total protein and total albumin, as well as ALT and LDH activities (U/L) were determined by a diagnostic kit (Dia Sys Diagnostic Systems, Germany). The optical density was measured with Perkin Elmer UV/VIS spectrophotometer Lambda EZ201.

Statistical analyses: Statistical analyses was carried out with SPSS model 17.0. for windows. The specific variables statistical significances was assessed by one-way ANOVA. P values $<0.05$ were considered to be significant.

\section{Results and Discussion}

To date more than 32 species of sea anemones have been reported to produce lethal peptides and proteins (Ferreiro et al., 2015; Visciano et al., 2016). For various special characteristics, sea anemone toxins are still desired for understanding the novel bioactive compounds focusing on their biological activity, characterization, and their mode of action (Ramezanpour et al., 2014; Utkin, 2015). In the present study, lethality appeared in rats once injected intraperitoneally with crude extract as well as fractionated proteins of $1 \mathrm{kDa}$ and $3 \mathrm{kDa}$, injecting higher showed dose of venom. The rats distinct neurotoxic signs and symptoms as restlessness, flexing of muscles, palpitation and hairs stand nape. As time advanced, paralysis of forelimbs, dragging of hind limbs, tonic convulsions, violent convulsions were observed, eventually leading to death. This finding suggests the notably neurotoxicological activity similar neurological observations have additionally been located in different cnidarian (Moghadasi et al., 2018; Madio et al., 2019). Till now the current study of marine toxins represent a structurally and toxicological diverse action. As recorded, most, but not all, exert their toxic effects by disrupting the nervous system synaptic transmission by the way of sodium channels blocking, Honma and Shiomi, (2006), protease inhibition(Alvarez et al., 2009) and AChE inhibition and brain biogenic amine levels disturbances (Honma and Shiomi, 2006) as well as cellular and structural brain damage in exposed animals (Prentis et al., 2018). In the cuttingedge study, histological observation from liver tissue of treated animal confirmed sinusoids enlargement, hepatocytes vacuole formations, white blood cells infiltrations and blood vessels congestion with hemorrhage (Fig. 2-5).

The results of the present study is in agreement with the findings of Yadappa et al. (2017) and Rjeibi et al. (2018), who reported that, crude extract and partially purified protein fractions intoxication results in deleterious disorganization and necrosis of hepatic cells and the diagnosed impact is in general established on the type of toxins, purification as well as dose level. Here, the hepatic histopathological impact was diagnosed in all the studied toxins and with extra powerful impact after intoxication with protein fraction of $1 \mathrm{kDa}$ (Fig. 4-5) and the crude extract has the much fewer effects (Fig. 2). The variable effects, however, can be defined on the basis of cytolytic impact on the examined toxins protein. Rojko et al. (2016) and Ramírez-Carreto et al. (2019), elucidated that distinct kinds of protein toxins that have been recognized from sea anemones and most can produce cytotoxicity due to the formation of pores. The pores produced alter the integrity of membrane and produce ionic imbalance that may lead to death and cell necrosis. However, the necrotic action exhibited by the toxins can also no longer be the only mechanism that causes cell death in view that there is elevating evidence by Yap and Hwang (2018) that pore-formation by toxins may set off apoptosis in the cells in a dose-dependent manner. In the current study, hepatic steatosis is one of the most identified commentary in the liver of animals that treated with fractionated protein.

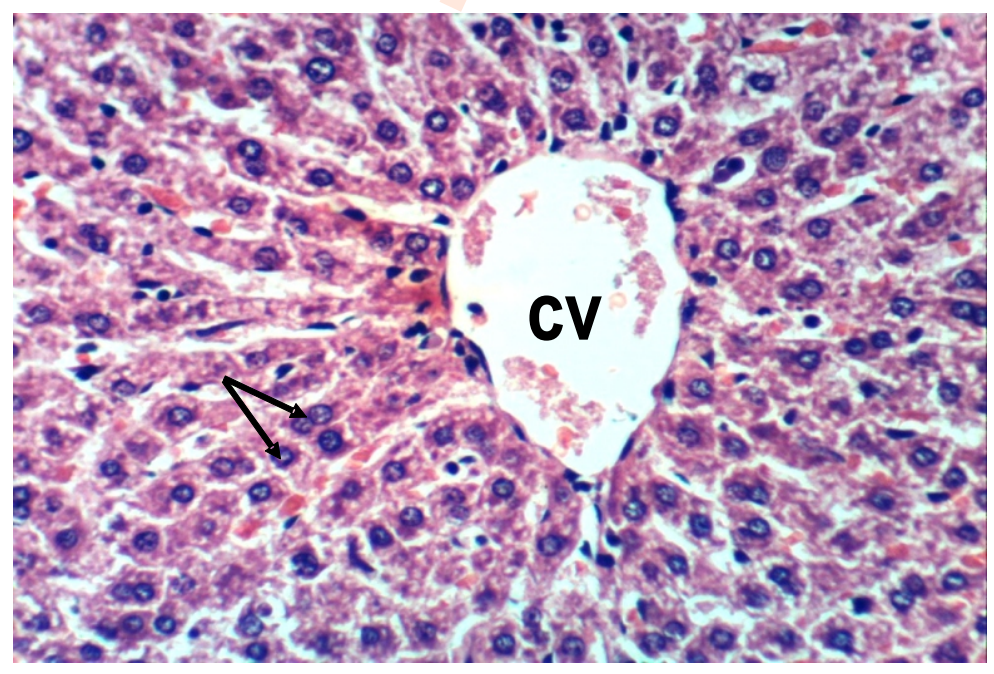

Fig. 1: Photomicrograph of liver section of male rats (control) showing normal hepatic structure, central vein (CV) and hepatocyte cell plates. The cells showed active vesicular nuclei and normal hepatic sinusoids (solid arrow) (H\&EX400). 


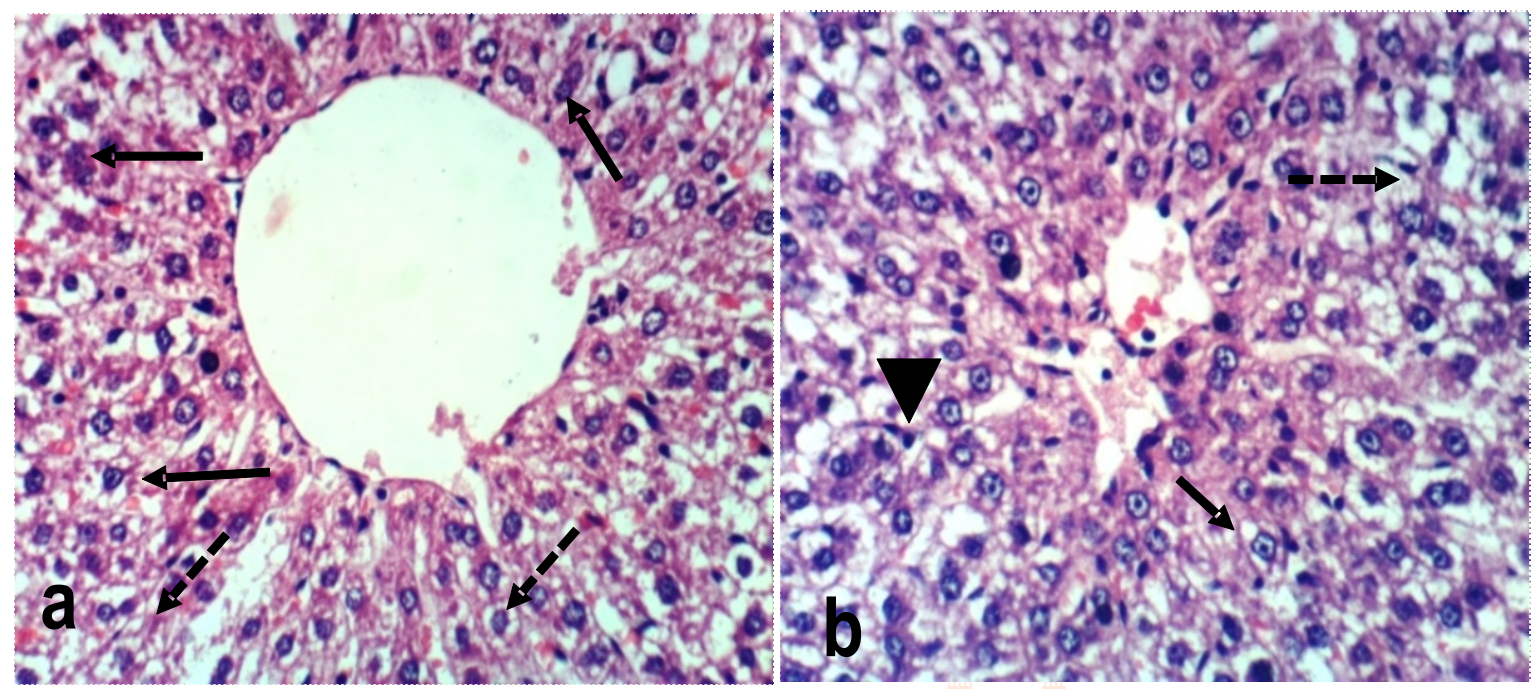

Fig. 2: Photomicrographs of liver sections of male rats post $7^{\text {th }}$ dose treatments with $\mathrm{G}$. helianthus crude extract (5.08 $\mathrm{mg} / \mathrm{kg}$ body), arrows indicating (a) polymorphic nuclear material in hepatocytes; (b) cytoplasmic vacuolation, necrosis (dash arrows) and fatty change (solid arrow) (H\&EX400).
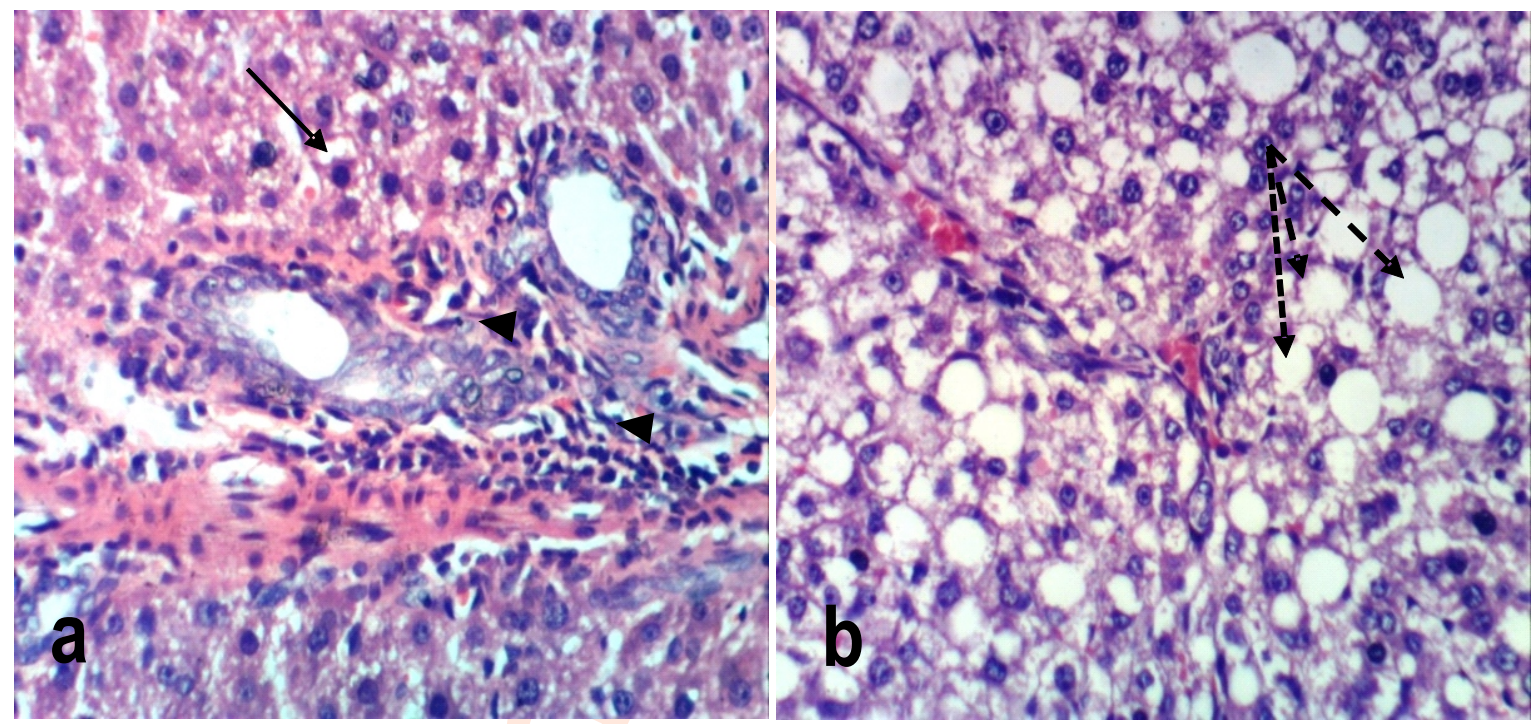

Fig. 3: Photomicrograph of liver sections of male rats of $7^{\text {th }}$ dose treatments with $G$. helianthus fractionated protein (3KDa), arrows indicating (a)focal hepatic necrosis (arrows) and inflammatory cells infiltration (head arrows), (b) apoptosis associated with hyperplasia of epithelial lining bile duct (dash arrows) (H\&EX400).

These findings are in agreement with Wahlang et al., (2013), who postulated that exposure to some chemical compounds may additionally lead to hepatic steatosis that can lead to inflammatory responses and lead to fibrosis and cirrhosis. Further, the exposure to toxins additionally produces harmful impact on the renal tissue. The most identified observations observed were atrophy and congestion of glomerular tuft, vacuolation of epithelial lining renal tubules, proliferation, cellular cast in the lumen of renal tubules, interstitial inflammatory cells infiltration, vacuolation and focal renal hemorrhage (Fig.7-9). These findings corroborated with the findings of previous study on the toxins isolated from different types of sea anemones (Mizuno et al., 2012). According to these investigators, the actual cell processes underlying the sea anemone toxins triggered nephrotoxicity are not but fully understood. Different indirect mechanisms of renal failure with sea anemone toxins have been 

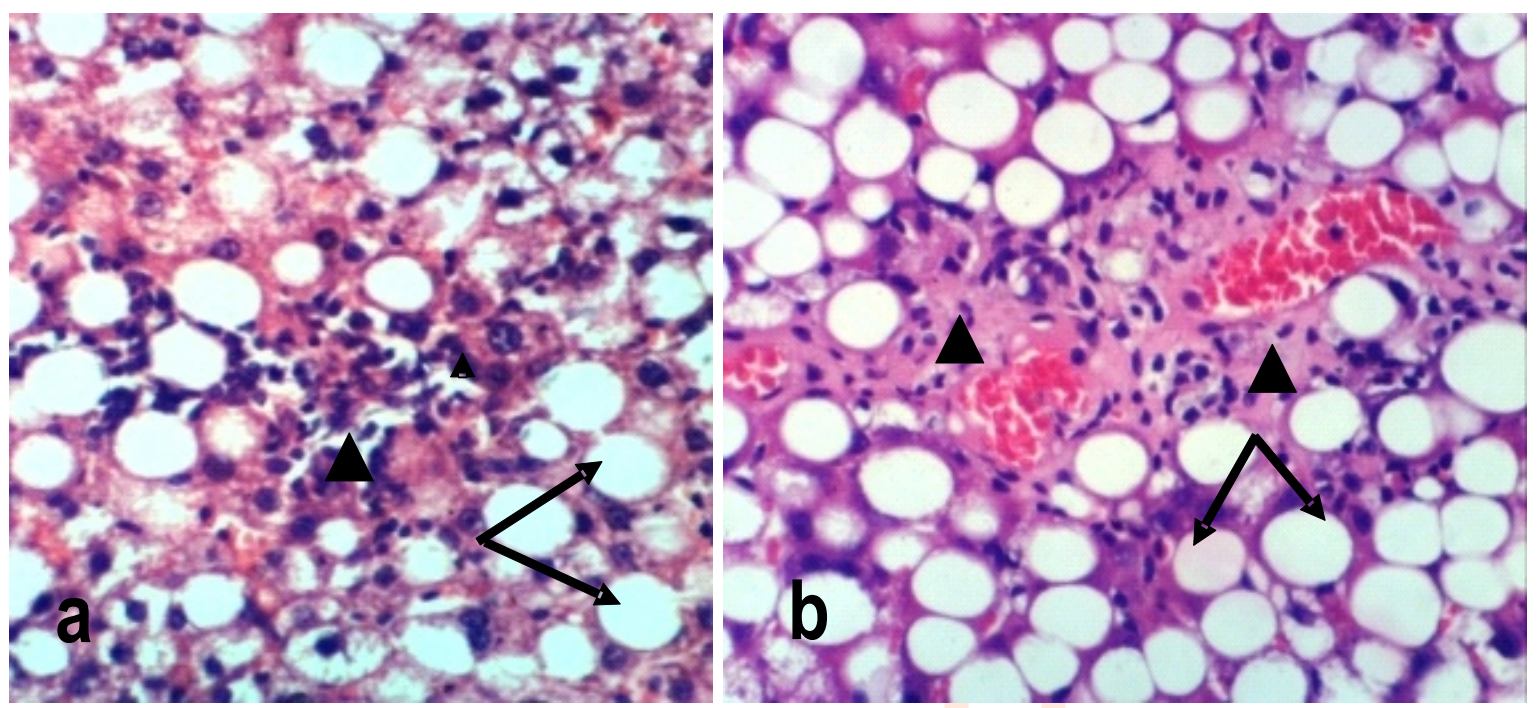

Fig. 4: Photomicrographs of liver of male rats of $7^{\text {th }}$ dose treatments with $G$. helianthus fractionated protein $(1 \mathrm{KDa})$ arrows indicating macrovesicular steatosis, focal inflammatory cells infiltration(head arrow), and focal hepatic necrosis (dash lines) (H\&EX400).

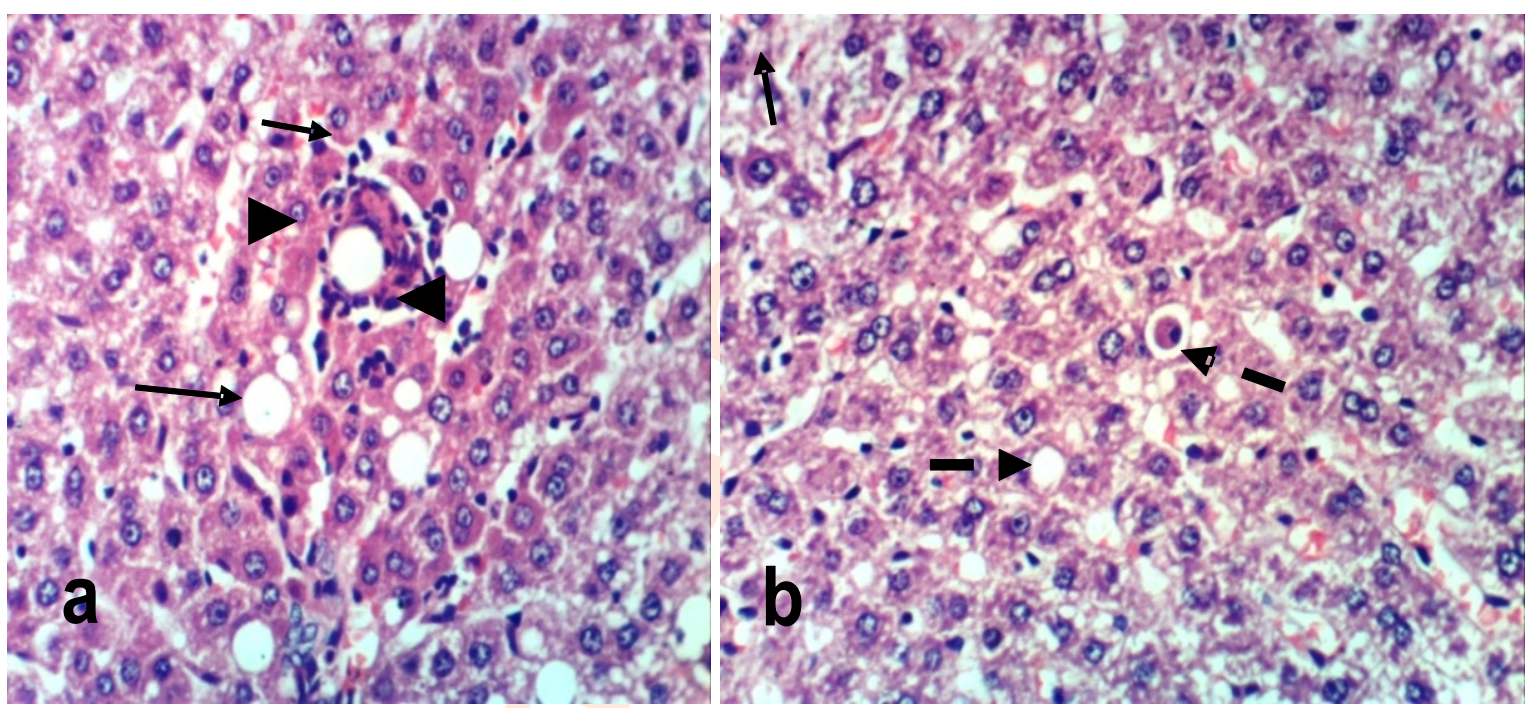

Fig. 5: Photomicrograph of liver sections of male rats post $7^{\text {th }}$ doses treatments with $\mathrm{G}$. helianthus fractionated protein (1KDa) arrows indicating (a) fatty change of hepatocytes, cytoplasmic vacuolization, and oval cells proliferation (head arrow); (b) cytoplasmic vacuolization and apoptosis of hepatocytes (dash arrows) (H\&EX400).

discussed. Oshiro et al. (2004), reported that renal damage is related with complement activating factors in the venoms that indirectly contribute to renal tissue damage. Ramkumar et al. (2012), demonstrated that nephrotoxicity can also be due to glomerular filtration which leads to excessive localization of venom in the kidney. Additionally, it may be associated to heart hemolysis that may motive renal block and subsequently inflicting kidney cells injury (Berger et al., 2015).
In the existing study, with the exception of total bilirubin which is highly and significantly lowered throughout the tested toxins, ALT and LDH and total protein are significantly elevated. Moreover, the degree of change varies as the type of the tested toxin. In this regard elevated ALT and total protein are seen post treatments $3 \mathrm{KDa}$ and $\mathrm{LDH}$ after intoxication with protein fraction of $1 \mathrm{KDa}$ (Table 1).These changes may be due the action of anemone toxins on the organ systems and varying detoxification 


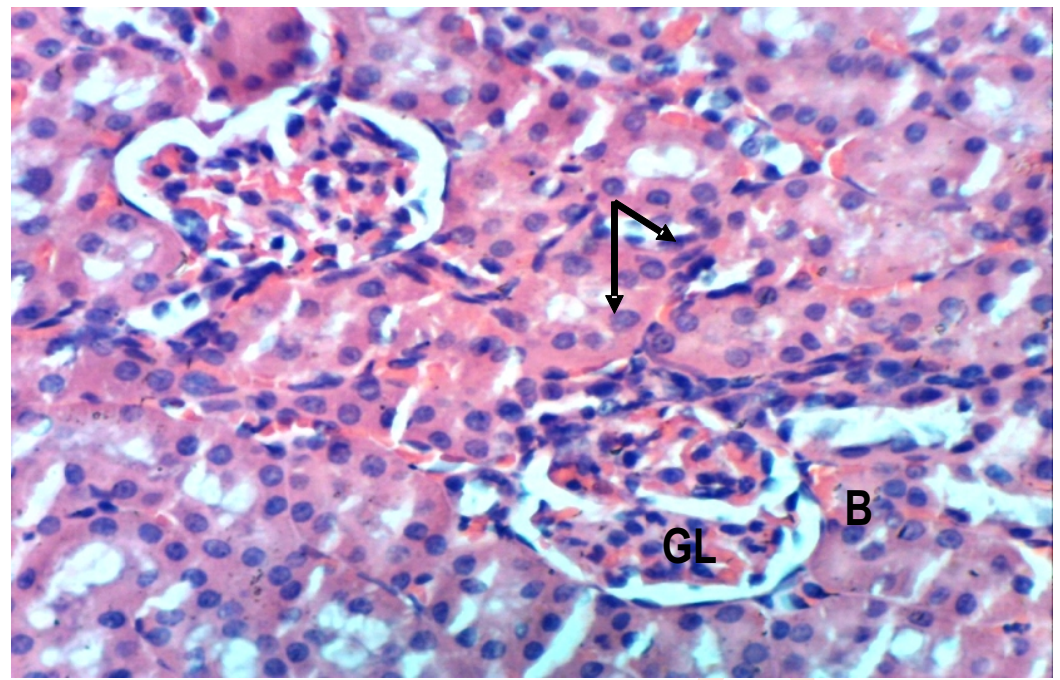

Fig. 6: Photomicrograph of kidney section of male rats of control group showing normal histological structure of renal parenchyma, normal Bowman's capsule (BC), glomeruli (GL) and normal renal lobules (arrows) (H\&EX400).

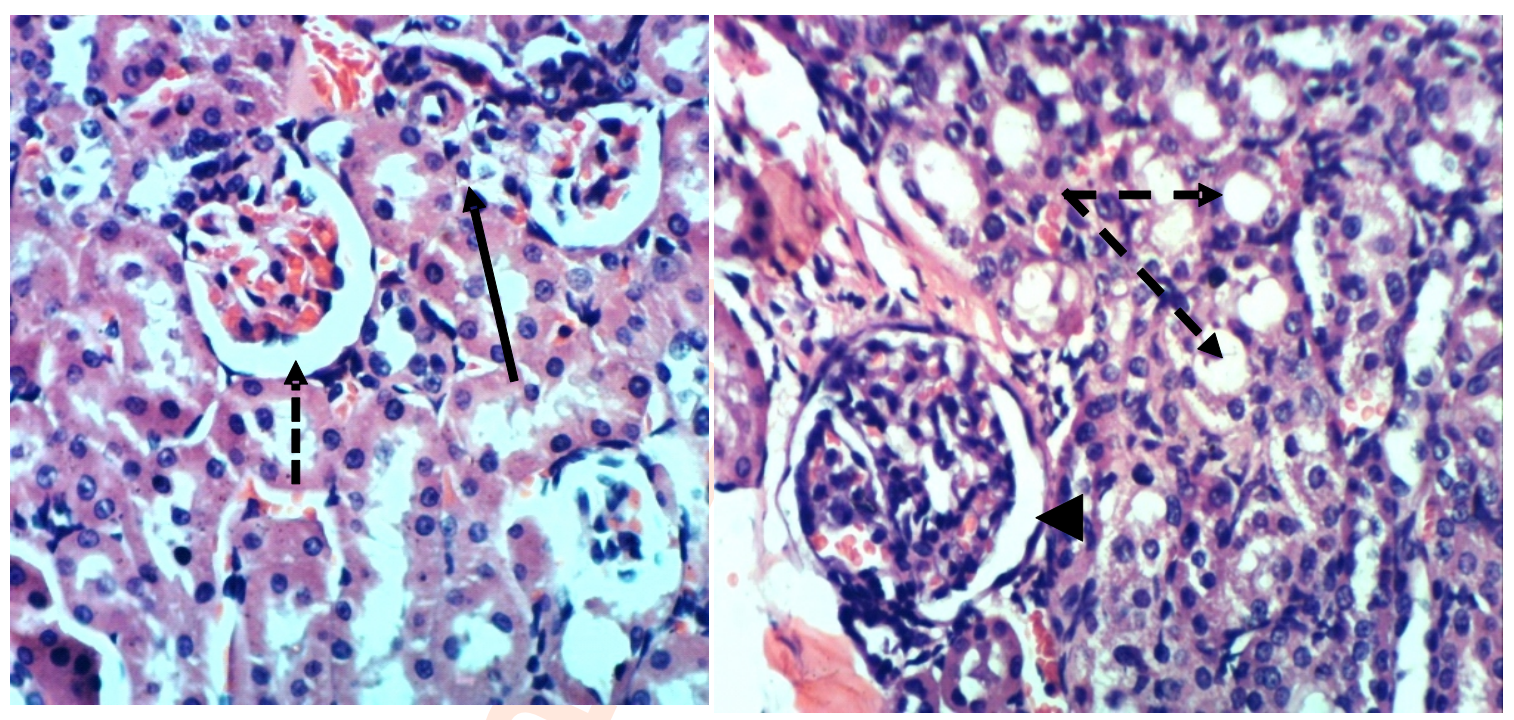

Fig. 7: Photomicrograph of kidney sections of male rats post treatments with crude extract of $G$. hileanthus arrows indicating (a) atrophy of glomerular tuft, vacuolation of epithelial lining renal tubules ( dash arrow) and (b) thickening of parietal layer of Bowman's capsule( head arrow) and fatty change (dash arrows) (H\&EX400).

processes. As described by several investigators the change in the studied serum bio-chemicals reflect liver and kidney tissue damage (Luo et al., 2014; Qin et al., 2016). As stated by Hu et al. (2011), actinoporin protein remoted from the sea anemone Stichodactyla Gigantea motives significant increase in ALT activity. Also, as mentioned recently by Ramírez-Carreto et al. (2019), the venom isolated from the sea anemone Anthopleura dowii Verrill causes release of $\mathrm{LDH}$ in proportion to the quantity of poisonous dose level and protein fraction type. Moreover, much of research have indicated the possible relationship between low bilirubin range and toxicity injured impact on of sea anemone toxins on cardiac (Ravindran etal., 2010) and neuronal cells (Kvetkina et al., 2020).

In addition, the studied toxins raised serum whole protein levels which in accordance with Lukačínová et al., 2011; Ekam et al., 2012 and Ye et al., 2020 working on different hepatoxic and nephrotoxic agents. Elevations in ALT and LDH and low bilirubin denotes injured hepatic and renal cells and reflect a consequence 

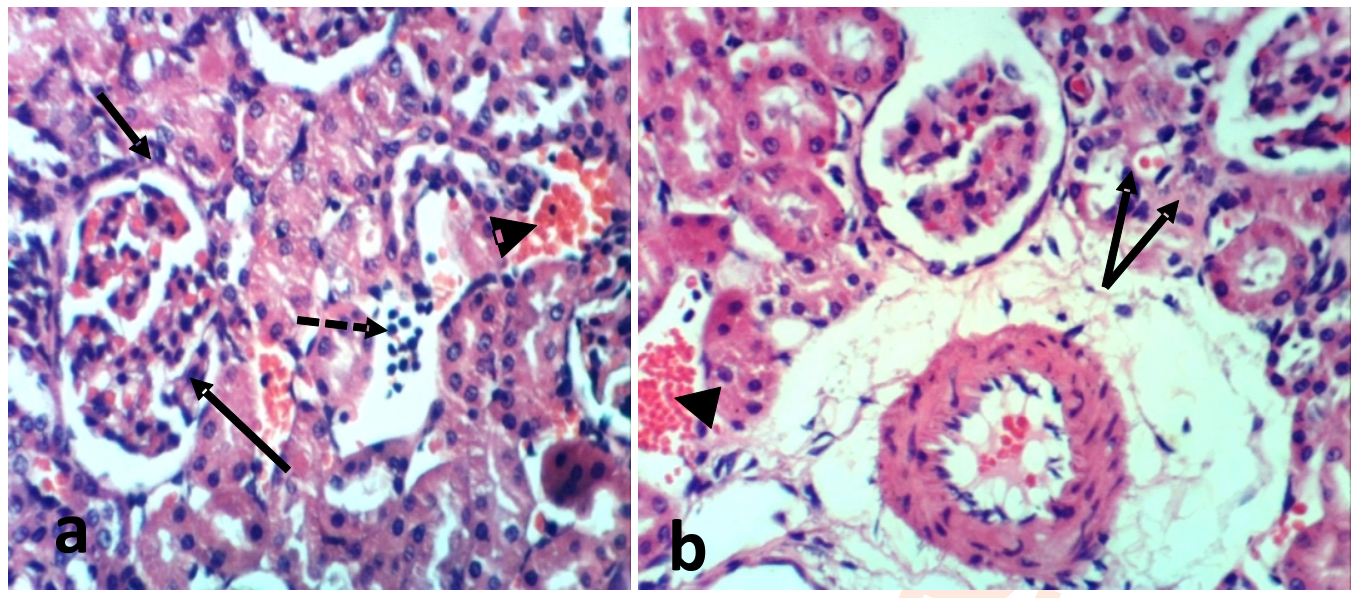

Fig. 8: Photomicrograph of kidney sections of male rats post treatments with 3Kda extract of $G$. hileanthus extract arrows indicating (a) slight atrophy and congestion of glomerular tuft and renal blood vessel, presence of cellular cast in the lumen of renal tubules (dash arrow)and occlusions with hemolyzed blood (head arrow), (b) interstitial fibroblasts proliferation, vacuolation of epithelial lining renal tubules and perivascular oedema (head arrow) (H\&EX400)
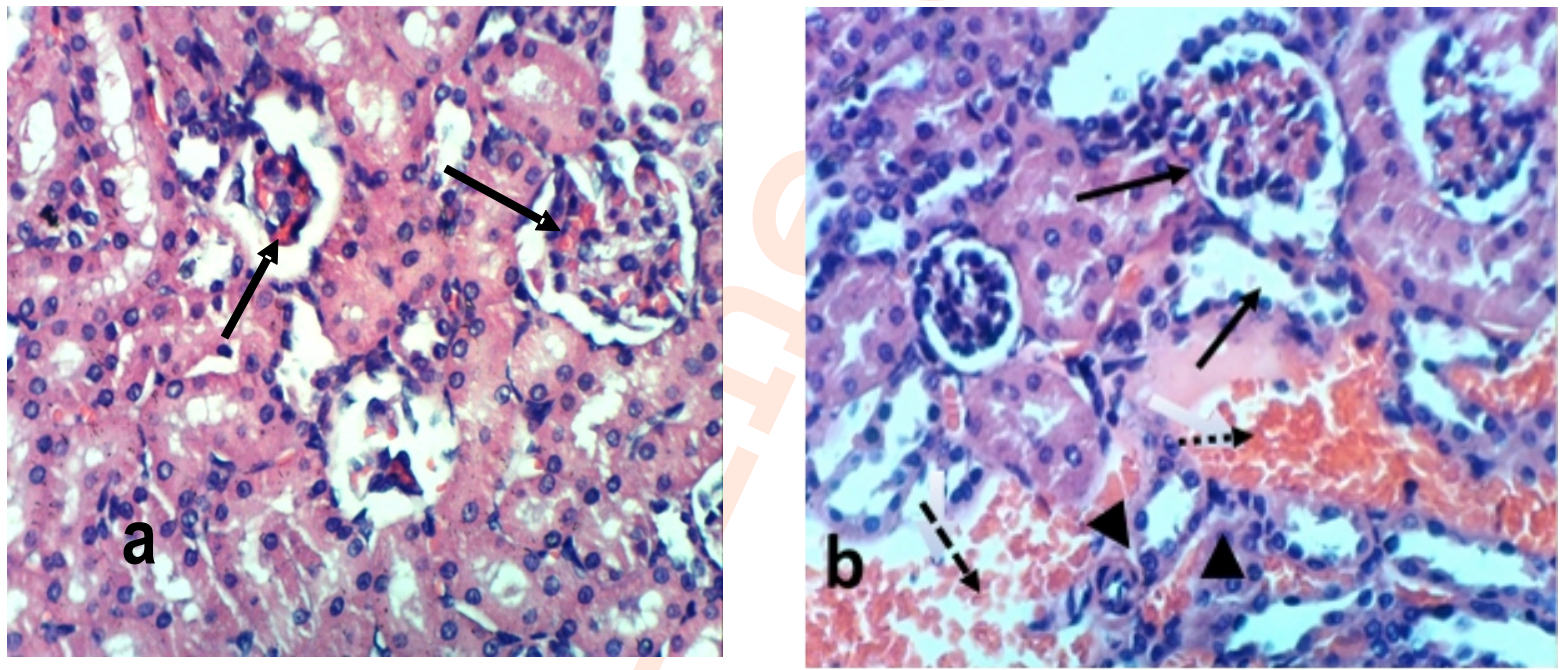

Fig. 9: Photomicrograph of kidney sections of male rats post treatments with $5.08 \mathrm{mg} \mathrm{kg}^{-1}$ of sea anemone $\mathrm{G}$. helianthus fractionated protein (1 $\mathrm{KDa}$ ) arrows indicating (a) hypertrophy of glomerular tuft and interstitial nephritis, (b) interstitial cells infiltration (head arrows) and focal renal hemorrhage with hemolyzed blood (dash lines) (Eand HX400).

Table 1: Effect of crude and partially purified protein of $G$. helianthus on the levels of some biochemical parameter

\begin{tabular}{lllll}
\hline Parameter & control & Crude extract & Protein fraction(1kDa) & Protein fraction (3kDa) \\
\hline ALT $\left(\mathrm{U} \mathrm{dL}^{-1}\right)$ & $16.973 \pm 1.44$ & $21.65 \pm 1.44^{*}$ & $20.30 \pm 1.46^{*}$ & $24.441 \pm 1.43^{*}$ \\
$\mathrm{LDH}\left(\mathrm{U} \mathrm{L}^{-1}\right)$ & $1579.01 \pm 87.30$ & $2429.450 \pm 52.14^{* *}$ & $2434.44 \pm 55.35^{* *}$ & $1279.38 \pm 84.65^{* *}$ \\
Bilirubin $\left(\mathrm{mg} \mathrm{dL}^{-1}\right)$ & $1.93 \pm 0.44$ & $0.248 \pm 0.047^{* *}$ & $0.46875 \pm 0.04^{* *}$ & $0.49375 \pm 0.08^{* *}$ \\
Protein $\left(\mathrm{g} \mathrm{dL}^{-1}\right)$ & $5.042 \pm 0.26$ & $6.376 \pm 0.73^{*}$ & $7.287=0.41^{* *}$ & $8.585 \pm 0.35^{* *}$ \\
Albumin $\left(\mathrm{g} \mathrm{dL}^{-1}\right)$ & $3.299 \pm 0.18$ & $3.402 \pm 0.16$ & $3.474 \pm 0.15$ & $3.221 \pm 0.16$ \\
\hline
\end{tabular}

Values are as means of six replicate \pm S.E.; ANOVA was used for determination of significance $\left({ }^{*} p \leq 0.05\right) .{ }^{*}$ significant, ${ }^{* *}$ highly significant 
of inflammation, injury and cell death as diagnosed in the present histological examinations. Apoptotic cell death, inflammation and necrosis can be idea of as cell implosion; that leads to loss of cell membrane and leakage of proteins into the extracellular space and plasma. Overall, even though cell dying, and plasma membrane damage may additionally recommend the dominant reasons of serum biochemical modifications post treatments, it is additionally feasible that different mechanisms can also play a role in the recorded biochemical results.

\section{Acknowledgments}

I would like thank to Prof. Sayed Rawi University of Jeddah and Dr Osama Mohamed Ahmed, Beni-Suef University, for their useful planning and careful reading. In addition, my honest perception goes to the participants of micro-technique units, National Cancer Institute Egypt for amenities provided and technical histological preparations.

\section{Add-on Information}

Authors' contribution: Turki M. Al-Shaikh: Author designed and performed the research, collected, analyzed and interpreted data and drafted manuscript. The author read and approved the final version.

Research content: The research contents is original and has not been published elsewhere

Ethical approval: NotApplicable.

Conflict of interest: The author declares that there is no conflict of interest.

Data from other sources: NotApplicable

Consent to publish: All authors agree to publish the paper in Journal of Environmental Biology.

\section{References}

Al-Hazmi, M.A., M.N. Gomma, A.S. Waggas and S.M. Rawi: Brain biogenic monoamines in relation to brain histopathology and plasma glutathione shuttle in rat after exposure to sea anemone Gyrostoma helianthus extract. Bioequiva. J. Bioequiv. Availab., 7, 005-011 (2015).

Álvarez, C., M.J. Mancheño., D. Martínez, M. Tejuca, F. Pazos and M E. Lanio: Sticholysins, two pore-forming toxins produced by the Caribbean sea anemone Stichodactyla helianthus: Their interaction with membranes. Toxicon, 8, 1135-1147 (2009).

Anderluh, G. and P. Maček: Cytolytic peptide and protein toxins from sea anemones (Anthozoa: Actiniaria). Toxicon, 40, 111-124 (2002).

Berger, M., L. Santi, W.O. Beys-da-Silva, F.M. Oliveira, M.V. Caliari , J.R. Yates, M.A. Vieira and J.A. Guimarães: Mechanisms of acute kidney injury induced by experimental Lonomia obliqua envenomation. Arch. Toxicol., 289, 459-483 (2015).

Bruhn, T., C. Schaller, C. Schulze, J. Sanchez-Rodriguez, C. Dannmeier, U. Ravens., J.F. Heubach, K. Eckhardt, J. Schmidtmayer, H.
Schmidt, A. Aneiros, E. Wachter and L. Béress: Isolation and characterization of five neurotoxic and cardiotoxic polypeptides from the sea anemone Anthopleura elegantissima. Toxicon, 39, 693-702 (2001).

Ekam, V. S., J.T. Johnson, K. Dasofunjo, M.O. Odey and S.E. Anyahara: Total protein, albumin and globulin levels following the administration of activity directed fractions of Vernonia amygdalina during acetaminophen induced hepatotoxicity in Wistar rats. Ann. Biol. Res., 3, 5590-5594 (2012)

Ferreiro, S.F., C. Carrera, N. Vilariño, M.C. Louzao, G. Santamarina, A.G. Cantalapiedra and L.M. Botana: Acute cardiotoxicity evaluation of the marine biotoxins OA, DTX-1 and YTX. Toxins, 7, 1030-1047(2015).

Frazão, B., V. Vasconcelos and A. Antunes: Sea anemone (Cnidaria, Anthozoa, Actiniaria) toxins: An overview. Mar. Drugs, 10, 1812-1851(2012).

Garcia, P.J., R.M. Schein and J.W. Burnett: Fulminant hepatic failure from a sea anemone sting. Ann. Int. Med., 120, 665-666 (1994).

García-Linares, S., E. Rivera-de-Torre, K. Morante, K. Tsumoto, J.M.M. Caaveiro, J.G. Gavilanes, J.P. Slotte and Á. Martínez-del-Pozo: Differential effect of membrane composition on the pore-forming ability of four different sea anemone actinoporins. Biochemistry, 55, 6630-6641 (2016).

Honma, T. and K. Shiomi: Peptide toxins in sea anemones: Structural and functional aspects. Mar. Biotechnol., 8, 1-10 (2006)

Hu, B., W. Guo, L. Wang, J. Wang, X. Liu and B. Jiao: Purification and characterization of Gigantoxin-4, a new actinoporin from the sea anemone Stichodactyla Gigantea. Int. J. Biol. Sci., 7, 729-739 (2011)

Humason, G. L.: Animal Tissue Techniques. $4^{\text {th }}$ Edn., W.H. Freeman and S. Francisco USA (1978).

Kvetkina, A., E. Leychenko, V. Chausova, E. Zelepuga,N. Chernysheva, K. Guzev, E. Pislyagin, E. Yurchenko, E. Menchinskaya, D. Aminin, L. Kaluzhskiy, A. Ivanov, S. Peigneur, J. Tytgat, E. Kozlovskaya and $M$. Isaeva: A new multigene $\mathrm{HCIQ}$ subfamily from the sea anemone Heteractis crispa encodes Kunitz-peptides exhibiting neuroprotective activity against 6-hydroxydopamine. Sci. Rep., 10 $4205(2020)$

Litchfield, J.T. and F. Wilcoxan: A simplified method of evaluating doseeffect experiments. J. Pharmacol. Expt. Ther., 96, 99-113 (1949).

Lukačínová. A., O. Rácz, E. Lovásová and F. Ništiar: Effect of lifetime low dose exposure to heavy metals on selected serum proteins of Wistar rats during three subsequent generations. Ecotoxicol. Environ. Saf., 74, 1747-55 (2011).

Luo, L., S. Schomaker, C. Houle, J. Aubrecht and J.L. Colangelo: Evaluation of serum bile acid profiles as biomarkers of liver injury in rodents. Toxicol. Sci., 137, 12-25(2014).

Madio, B., F. Glenn, G.F. King and E.A.B. Undheim: Marine Biotoxins: Occurrence, Toxicity, regulatory limits and reference methods. Front. Microbiol., 7, 1051 (2019).

Mizuno, M., L. Yasuhiko and B.P. Morgan: Exploiting the nephrotoxic effects of venom from the sea anemone, Phyllodiscus semoni, to create a hemolytic uremic syndrome model in the rat. Mar. Drugs, 10, 1582-1604 (2012)

Moghadasi, Z., S. Jamili, D. Shahbazadeh and K.P. Bagheri: Toxicity and potential pharmacological activities in the Persian Gulf venomous sea anemone, Stichodactyla haddoni. Iran J. Pharm. Res., 17, 940-955(2018).

Oshiro, N., C. Kobayashi, S. I. wanaga, M. Nozaki, M. Namikoshi, J. Spring and H.A. Nagai: New membrane-attack complex/perforin (MACPF) domain lethal toxin from the nematocyst venom of the Okinawan sea anemone Actineria villosa. Toxicon, 43, 225-228 (2004). 
Prentis, P.J., A. Pavasovic and R.S. Norton: Sea Anemones: Quiet achievers in the field of peptide toxins. Toxins (Basel), 10, 36 (2018). https://doi.org/10.3390/toxins10010036

Qin, S., Y. Zhou, L. Gray, U. Kusebach, L. McEvoy, D.J. Antoine, L. Hampson, K.B. Park, D. Campbell, J. Caballero, G. Glusman, X. Yan, T.K. Kim, Y. Yuan, K. Wang, L. Rowen, R.L. Moritz, G.S. Omenn, M. Pirmohamed and L. Hood: Identification of organenriched protein biomarkers of acute liver injury by targeted quantitative proteomics of blood in acetaminophen- and carbontetrachloride-treated mouse models and acetaminophen overdose patients. J. Proteome. Res., 15, 3724-3740 (2016).

Ramezanpour, M., K. Burke da Silva and B.J.S. Sanderson: The effect of sea anemone ( $H$. magnifica) venom on two human breast cancer lines: death by apoptosis. Cytotechnology, 66, 845-852 (2014).

Ramírez-Carreto, S., R. Vera-Estrella, T. Portillo-Bobadilla, A. LiceaNavarro, J. Bernaldez-Sarabia, E. Rudiño-Piñera, J. Verleyen, S. Rodríguez and C. Rodríguez-Almazán: Transcriptomic and proteomic analysis of the tentacles and mucus of Anthopleura dowii Verrill. 1869. Mar. Drugs, 17, 436 (2019).

Ramkumar, S., A S. Sudhagar and K. Venkateshvaran: Bioactivity of venom extracted from the sea anemone Anthopleura asiatica (Cnidaria: Anthozoa): Toxicity and histopathological studies. Int. J. Fisher. Aquacul., 4, 71-76 (2012).

Ravindran, J., T. Samuel, E. Alex and J. William: Adulticidal activity of Ageratum houstonianum Mill. (Asteraceae) leaf extracts against three vector mosquito species (Diptera: Culicidae). Asian Pac. J. Trop. Dis., 2,177-179 (2012).
Ravindran, V.S., L. Kannan and K. Venkateshvaran: Biological activity of sea anemone proteins: I. Toxicity and histopathology. Indian J. Exp. Biol., 48, 1225-1232(2010).

Rjeibi, I., A. Feriani, A. BenSaad, J. Sdayria, I. Saidi, S. Ncib, S. Souid, M.S. Allagui and N. Hfaiedh: Lycium europaeum extract: A new potential antioxidant source against cisplatin-induced liver and kidney injuries in mice. Oxid. Medi. Cell. Long., 2018, 1-9 (2018).

Rojko, N., M.D. Serra, P. Maček and G. Anderluh: Pore formation by actinoporins, cytolysins from sea anemones. Biochim. Biophys. Acta., 1858, 446-456 (2016).

Suput, D.: In-vivo effects of cnidarian toxins and venoms. Toxicon, 54,1190-1200 (2009)

Utkin, Y.N.: Animal venom studies: Current benefits and future developments. World J. Biol. Chem., 6, 28-33 (2015).

Visciano, P., M. Schirone, M. Berti, A. Milandri, R. Tofalo and G. Suzzi: Marine Biotoxins: Occurrence, toxicity, regulatory limits and reference methods. Front Microbiol., 7, 1051 (2016).

Wahlang, B., I.B. Juliane, H.B. Clair, H.J. Bellis-Jones, K.C. Falkner, C.J. McClain and M.C. Cave: Toxicant-associated steatohepatitis. Toxicol. Pathol., 41, 343-360 (2013).

Yadappa, K.S., B.B. Kaliwal, Y. Suvarnarajesh, M. Krishnapur and S.C. Kaliwalm: Dysfunction of liver and kidney induced by ethion on albino mice. Int. Res. J. Manag. Sci. Technol., 8, 2348-9367 (2017).

Yap, W.Y. and J.S. Hwang: Response of cellular innate immunity to cnidarian pore-forming toxins. Molecules, 23, 2537 (2018).

Ye W. , T. Liu ,W. Zhang ,M. Zhu,Z. Liu,Y. Kong and S Liu: Marine toxins detection by biosensors based on aptamers toxins, 12,1 (2020). doi: 10.3390/toxins 12010001 